\title{
Phylogeography of the bivalve Tegillarca granosa in coastal China: implications for management and conservation
}

\author{
Gang Ni, Qi Li*, Lingfeng Kong, Xiaodong Zheng \\ The Key Laboratory of Mariculture, Ministry of Education, Ocean University of China, Qingdao 266003, PR China
}

\begin{abstract}
Present genetic patterns of marine organisms not only result from historical and contemporary ecological factors, but also from anthropogenic activities. Disentangling the relative effects of these factors can provide valuable insights into management and protection of exploitable species. The commercially important marine clam Tegillarca granosa is representative of species that are translocated within East Asia for coastal aquaculture purposes. We conducted a nucleotide sequence analysis of mitochondrial cytochrome $c$ oxidase subunit I and nuclear internal transcribed spacer 1 markers in T. granosa to investigate its genetic diversity and distribution in 2 marginal seas (the East and South China Seas) of the northwestern Pacific. Based on phylogenetic inferences, we identified 2 evolutionarily significant units (ESUs) with high genetic distance between them for both markers. The high genetic distance may be associated with the historical isolation of the marginal seas during low sea level periods. One ESU was widely distributed in both seas, whereas the other was restricted to 2 disjunct localities in the South China Sea. Based on the isolation by distance analysis $(p=0.068)$ and comparison of patterns of co-occurring species, this pattern appears to be mostly attributable to the human-mediated translocations among coastal waters rather than natural range expansion. Furthermore, from a conservation viewpoint, the southern ESU is now facing high extinction risk because of mitochondrial introgression and smaller, fragmented populations; consequently, immediate proper management is required to protect the endangered populations representing this lineage.
\end{abstract}

KEY WORDS: Population genetics - Aquaculture species · Evolutionarily significant units · ESUs · Marginal sea $\cdot$ Human activity $\cdot$ Genetic conservation · East Asia

\section{INTRODUCTION}

Identifying processes that shape the spatial distribution of genetic diversity is a crucial step in population and conservation genetics (Hoban et al. 2010). The marine environment, however, is still a challenging area for such genetic surveys, as complex abiotic and biotic factors can ultimately affect population structure on different temporal and spatial scales (Sponaugle et al. 2002, Hellberg 2009). A consensus reached in recent marine phylogeography studies is that Pliocene and Pleistocene glaciations had a sub- stantial effect on the genetic patterns of coastal taxa in the northern hemisphere (e.g. North Atlantic, Wares 2002; Indo-Pacific, Kochzius et al. 2009); most of these patterns can be interpreted in the context of marine basins having been isolated during periods of low sea levels.

A similar scenario has also been illustrated in 2 marginal seas of the northwestern Pacific: the East China Sea (ECS) and the South China Sea (SCS), along the coastline of China (Fig. 1). During the PlioPleistocene period, when glaciers began advancing 3.5 million yr (Myr) ago (Haq et al. 1987), the sea 


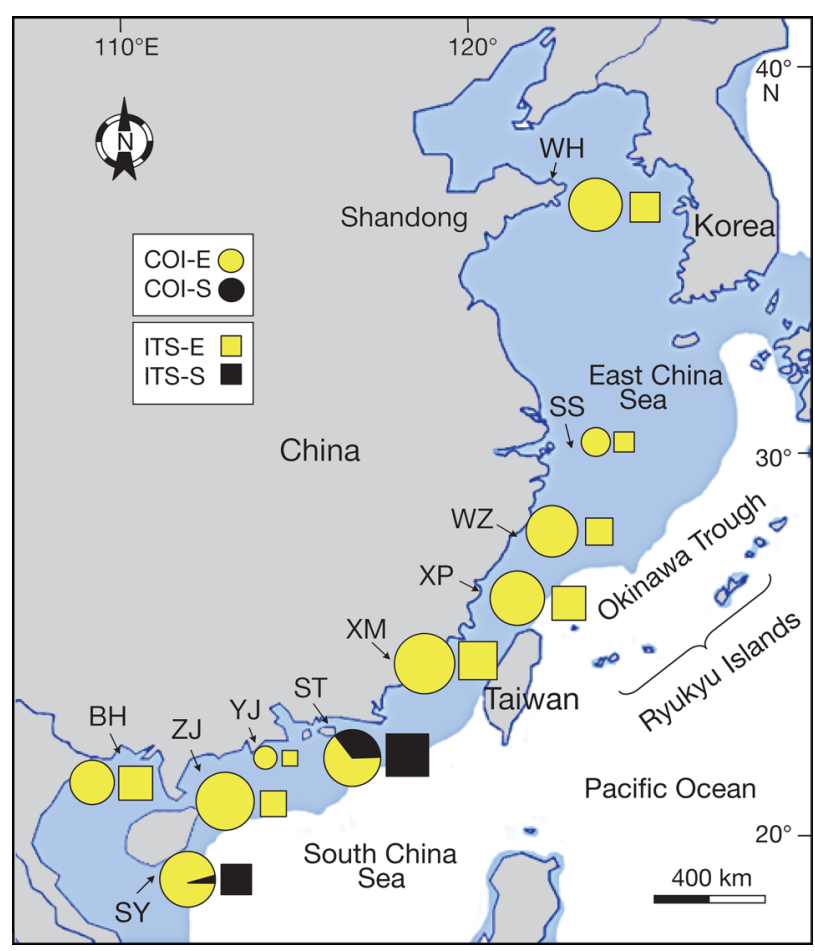

Fig. 1. Locations of sampled populations and distribution of each lineage of Tegillarca granosa. See Table 2 for abbreviations. The yellow and black circle and square sizes are proportional the amount of lineages found at each location. Blue shaded areas: seabed regions $<120 \mathrm{~m}$ depth that would have been exposed during a glacial period ( 3.5 Myr ago)

levels in the ECS and SCS were approx. 130 to $150 \mathrm{~m}$ and 100 to $120 \mathrm{~m}$ lower than present levels, respectively (Wang \& Sun 1994). Large land bridges extended from eastern China to Taiwan and the Ryukyus Islands (Fig. 1), likely leading to isolation of the East China Sea from the South China Sea and Pacific Ocean (Kimura 2000). A general pattern resulting from the separation has been revealed for marine species: each sea served as an independent refugium during glaciations and gave rise to deep genetic divergence between populations, which can be dated back to the Pliocene and middle Pleistocene (Liu et al. 2007, Kong \& Li 2009, Xu et al. 2009).

After the reconnection of the ESC and SCS as the sea levels rose, ocean currents would have been the most important factor for postglacial gene flow of formerly isolated populations. Studies on macroalgae and barnacles have clearly demonstrated the effect of oceanographic circulation on present-day genetic distribution as well as the formation of a hybrid zone in the northwestern Pacific (Tsang et al. 2008, Cheang et al. 2010). However, genetic patterns often vary among co-distributed taxa given e.g. the differentiations in fecundity, life histories, and dispersal capacity (Avise 1998, Lee \& Boulding 2009). For the redlip mullet Chelon haematocheilus, gene flow propelled by the currents between the ECS and SCS was limited, despite this species' relative long pelagic larvae stage duration (PLD) of 4 wk (Liu et al. 2007). Accumulated evidence suggests that the present genetic structuring in the marine realm is more likely a product of complex species-specific ecological processes than of oceanographic circulation patterns (Hu et al. 2011). From this point of view, hypotheses proposed for explaining the evolutionary history of 1 species may not be readily applicable to another, even when the 2 species have the same dispersal capacity (Marko 2004). Therefore, more phylogeographical and/or biogeographical studies are needed for a comprehensive understanding of the interactive effects of various historical and present-day factors on the genetic structures of marine organisms in East Asia (Xiao et al. 2010, Hu et al. 2011).

For coastal phylogeography studies, aquaculturerelated transfers of some species (e.g. molluscs) throughout their native ranges pose additional problems (e.g. Huvet et al. 2000, Zhou \& Allen 2003). Changes in spatial distribution by human-mediated dispersal can dramatically affect species' genetic diversity as well as population structure, leading to phylogeography patterns reflecting more than simply the effects of natural processes (Benke et al. 2009). In addition, hybridization occurring between diverged populations could have detrimental consequences such as genetic swamping and outbreeding depression (Utter 2000, Frankham 2010), which may indirectly increase the risk of reduced intraspecific genetic diversity. As a fundamental component of biodiversity, intraspecific genetic diversity is a driving force behind adaptation and evolutionary success (Allendorf \& Luikart 2007, Lind et al. 2007). These issues have been addressed in freshwater and terrestrial phylogeography studies (e.g. Benke et al. 2009, Hoban et al. 2010), but in marine environments, empirical studies are still required to assess the genetic impact of human activities, and to form a basis for biodiversity management and conservation.

A possible model species for addressing these research needs in East Asia is the eurythermal marine bivalve Tegillarca granosa, a benthic species widely distributed in the northwestern Pacific (Xu 1997). Due to its economic value, the demand for juvenile $T$. granosa grew dramatically in southern China since the 1980s and could no longer be met through local harvest. Although no precise data are available, large amounts of seed and/or adult $T$. granosa from northern provinces (such as Shandong) were frequently 
transported to southern provinces (Zheng et al. 1995) and then cultured in open water along the coastline. These aquacultural practices likely mixed evolutionarily separated lineages and thus altered the genetic composition of the native region. Previous studies using isozymes (Wang et al. 2005) and mitochondrial DNA (Zheng et al. 2009) showed differentiation between the ECS and SCS populations. However, due to low sampling size, neither the genetic patterns nor the mechanisms driving genetic differentiation could be fully explained in these studies. Moreover, genetic splits between populations are indicative of cryptic taxonomic divisions, which should be further validated based on evidence from both mitochondrial and nuclear sequences. In the present study, 2 target markers - portions of the mitochondrial cytochrome $C$ oxidase subunit I (mtCOI) gene and nuclear internal transcribed spacer 1 (ncITS) - were used to investigate the intraspecific phylogeography of T. granosa in the ECS and SCS. We aimed to provide insight into the complex interactions of historical and contemporary factors, including human-mediated translocation of $T$. granosa on its genetic pattern in 2 marginal seas along the Chinese coast, with a focus on the clam's taxonomy and conservation.

\section{MATERIALS AND METHODS}

\section{Sampling}

A total of 179 Tegillarca granosa samples were obtained from 10 localities between April 2008 and June 2010, encompassing the species' major geographical distribution in the ECS and SCS (Fig. 1). Because it was impossible to distinguish the culture and wild individuals (Li et al. 2003), we avoided sampling from the known aquaculture zones. Efforts were made to achieve a relatively high sample size $(\mathrm{N} \geq 14)$ for each population. However, for 2 populations (Shengsi in the ECS and Yangjiang in the SCS) we were only able to collect 6 and 4 clams, respectively. The adductor muscle was excised from each clam and stored in $95 \%$ ethanol immediately before analysis. Whole genomic DNA was extracted from $50 \mathrm{mg}$ muscle tissue with a phenol/chloroform method described by Li et al. (2002).

\section{Primer selection and sequence acquisition}

As the COI gene of a large number of samples was not amplified by the universal primers LCO-1490 and
HCO-2198 (Folmer et al. 1994), we used the COI sequences of Tegillarca granosa in GenBank (accession numbers: EF583524 to EF583540, FJ411459 to FJ411480) to design the internal primer pair COINF (5'-TTG ATA GGG ATC TGT TTA AGA-3'; forward primer) and COINR (5'-GCC AAT ACA GGC AAA GAA A-3'; reverse primer) for amplifying shorter COI gene fragments. For mtCOI, each polymerase chain reaction (PCR) was performed in $50 \mu \mathrm{l}$ volumes containing 2 U Taq DNA polymerase (Takara), $100 \mathrm{ng}$ template DNA, $0.25 \mu \mathrm{M}$ of each primer, $0.2 \mathrm{mM}$ dNTPs, $5 \mu \mathrm{l} 10 \times$ PCR buffer (final concentration: $1 \times$ PCR buffer) and $2 \mathrm{mM} \mathrm{MgCl}_{2}$. The PCR amplification was carried out on a GeneAmp ${ }^{\circledR} 9700$ PCR System (Applied Biosystems), and the cycling parameters were an initial denaturation at $94^{\circ} \mathrm{C}$ for $3 \mathrm{~min}, 35$ cycles of denaturation at $94^{\circ} \mathrm{C}$ for $1 \mathrm{~min}$, annealing at $50^{\circ} \mathrm{C}$ for $1 \mathrm{~min}$, and extension at $72^{\circ} \mathrm{C}$ for $1 \mathrm{~min}$, followed by a final extension at $72^{\circ} \mathrm{C}$ for $5 \mathrm{~min}$. The PCR products were subjected to electrophoresis on a $1.5 \%$ Tris-Borate-EDTA agarose gel, stained with ethidium bromide. The target fragment was purified directly using EZ Spin Column PCR Product Purification Kit (Sangon) following the manufactuer's protocol. The cleaned product was prepared for sequencing using the BigDye Terminator Cycle Sequencing Kit (v. 3.1, Applied Biosystems) and finally sequenced on an ABI PRISM 3730 (Applied Biosystems) automatic sequencer.

To confirm the status of the divergent lineages observed in the mtCOI, we also sequenced a portion of ribosomal ITS region (partial 5.8S, complete ITS-1 and partial 18S) using primers ITS-A and ITS-B (Gaffney et al. 1998). The ncITS PCR cocktails and conditions were as described above, except for the primer set and the annealing temperature $\left(55^{\circ} \mathrm{C}\right)$. The majority of samples yielded clear sequence data using a direct sequence method, while some individuals with 2 sequences of different lengths were resolved with CHAMPURU 1.0 software (Flot 2007). For samples yielding poor data using the direct sequence method, the PCR products were cloned into the plasmid pEASY-T1 (TransGen Biotech), and then 3 to 6 clones were picked at random for sequencing for each individual (Table 1).

\section{Sequence variation}

Sequences for each molecular marker were edited and aligned using DNASTAR software (DNASTAR), and then re-checked by eye. Gaps found in the ncITS alignment were treated as missing data in the subse- 
Table 1. Individuals cloned and number of clones sequenced (number of haplotypes) for the southern internal transcribed spacer lineage (ITS-S) in samples collected at Shantou (ST) and Sanya (SY) (see Fig. 1)

\begin{tabular}{|lcc|}
\hline Specimen & No. of clones & No. of haplotypes \\
\hline ST4 & 4 & 4 \\
ST12 & 4 & 3 \\
ST15 & 4 & 2 \\
ST18 & 4 & 4 \\
ST21 & 5 & 4 \\
SY5 & 6 & 5 \\
SY11 & 3 & 2 \\
SY15 & 5 & 4 \\
\hline
\end{tabular}

quent analysis. Molecular diversity indices such as number of haplotypes (n), haplotype diversity (h), nucleotide diversity $(\pi)$, and mean number of pairwise differences $(k)$ within each population were calculated using ARLEQUIN 3.5 (Excoffier \& Lischer 2010). Sequences of haplotypes for each marker have been deposited in the GenBank database with accession numbers HQ699337 to HQ699369 (mtCOI), and HQ699370 to HQ699436 and JN802225 to JN802253 (ncITS).

\section{Statistical analyses}

To examine genetic structure among populations, pairwise $\Phi_{\mathrm{ST}}$ values were calculated among 10 populations using combined mtCOI and ncITS sequences as implemented in ARLEQUIN 3.5 (Excoffier \& Lischer 2010). For samples with intraindividual ncITS polymorphisms, 1 random sequence was selected and used. Since these polymorphisms were mainly due to 1 or 2 indels, this random selection process is unlikely to have significantly affected our results. The significance of each pairwise comparison was tested by multiple permutations (10000 randomizations).

To better explain the dispersal pattern of Tegillarca granosa, we examined the association between the genetic differentiation and the shortest coastal distances (log-transformed) with Mantel tests using the IBD web service program (Jensen et al. 2005). Analyses were also performed for the northern and southern populations of the northern lineage (one of the 2 lineages we detected based on mtCOI sequence analysis) separately, using COI sequences. The significance of the correlation between 2 distance matrices was tested using permutation methods (10000 randomizations).
The program jModelTest (Guindon \& Gascuel 2003, Posada 2008) was utilized to determine the evolutionary model that best fitted the 2 loci using Akaike's information criterion (AIC). GTR + G was chosen as the best-fit model for both markers, and was used in the following phylogenetic analyses.

We combined 2 analytical approaches to achieve better phylogenetic resolution. First, to assess whether or not prominent patterns of intraspecific divergence existed, Bayesian inferences were performed in MrBayes v. 3.1 (Huelsenbeck \& Ronquist 2001). For the mtCOI phylogenetic tree, 14 Tegillarca granosa sequences (EF583526 to EF583528 and EF583530 to EF583540) from a previous study (Zheng et al. 2009) and a congeneric T. nodifera sequence (AB050893) used as outgroup were included in addition to the sequences obtained in the present study. The Markov-chain Monte Carlo search was run with 4 chains for 5 million (mtCOI) and 8 million (ncITS) generations with sampling frequency of $1 / 1000$ trees. Parameter stationarity was achieved when the standard deviation of split frequencies was $<0.01$ at 3 million (mtCOI) and 4 million (ncITS) generations. Trees sampled prior to stationarity were discarded as burn-in, and then a 50\% consensus tree with branch lengths was constructed with the remaining 2001 (for mtCOI) and 4001 trees (for ncITS). Second, to resolve shallow relationships among closely related haplotypes and gain insight into the mutation process, haplotype networks were estimated using the HapStar software (Teacher \& Griffiths 2011), which can automatically lay out the network for easy visualization. Mean sequence divergence within and between the major lineages of each marker was calculated in MEGA v. 5 (Tamura et al. 2011) using the $p$-distance model.

\section{RESULTS}

A 496 bp segment of the mtCOI gene region was amplified and sequenced for 179 individuals. The alignment had a total of 63 parsimony informative sites representing 33 unique haplotypes (see Table 3). The number of haplotypes per population ranged from 1 to 13, and all populations but 2 (Shantou [ST] and Sanya [SY]) showed extremely low haplotype diversity $\left(h_{\mathrm{COI}}=0\right.$ to 0.495 ; Table 2$)$. ST and SY displayed the highest genetic variation with haplotype diversity of 0.905 and 0.892 , respectively. Only 2 haplotypes (Hap.01 and Hap.02) were discovered in $>1$ population: Hap.01, which was well-represented in all populations except ST, was the most abundant one 
Table 2. Tegillarca granosa. Sampled populations, number of individuals sequenced per population per locus ( $N_{i}$ parentheses: total number of sequences included), number of haplotypes $(n)$, haplotype diversity $(h)$, nucleotide diversity $(\pi)$, and mean number of pairwise differences $(k)$ for clam populations surveyed in the present study. Subscripts indicate variables for mitochondrial cytochrome $c$ oxidase subunit I (mtCOI) or nuclear internal transcribed spacer 1 (ncITS)

\begin{tabular}{|c|c|c|c|c|c|c|c|c|c|c|}
\hline \multirow{2}{*}{ Population } & \multicolumn{5}{|c|}{-mtCOI- } & \multicolumn{5}{|c|}{-ncITS } \\
\hline & $N_{\mathrm{COI}}$ & $n_{\mathrm{COI}}$ & $h_{\mathrm{COI}}$ & $\pi_{\mathrm{COI}}$ & $k_{\mathrm{COI}}$ & $N_{\text {ITS }}$ & $n_{\text {ITS }}$ & $h_{\mathrm{ITS}}$ & $\pi_{\mathrm{ITS}}$ & $k_{\text {ITS }}$ \\
\hline \multicolumn{11}{|l|}{ East China Sea } \\
\hline Weihai (WH) & 20 & 3 & 0.489 & 0.00161 & 0.805 & 11 & 10 & 0.982 & 0.00488 & 1.545 \\
\hline Shengsi (SS) & 6 & 2 & 0.333 & 0.00067 & 0.333 & 5 & 5 & 1.000 & 0.00505 & 1.600 \\
\hline Wenzhou (WZ) & 19 & 3 & 0.294 & 0.00010 & 0.503 & 9 & 6 & 0.917 & 0.00263 & 0.833 \\
\hline Xiapu (XP) & 21 & 3 & 0.495 & 0.00206 & 1.029 & 14 & 13 & 0.989 & 0.00379 & 1.198 \\
\hline Xiamen (XM) & 26 & 2 & 0.077 & 0.00015 & 0.077 & 18 & 16 & 0.987 & 0.00332 & 1.046 \\
\hline \multicolumn{11}{|l|}{ South China Sea } \\
\hline Shantou (ST) & 23 & 13 & 0.905 & 0.05610 & 28.04 & $23(39)$ & 24 & 0.800 & 0.00539 & 1.694 \\
\hline Yangjiang (YJ) & 4 & 1 & 0.000 & 0.00000 & 0.000 & 3 & 3 & 1.000 & 0.00421 & 1.333 \\
\hline Zhanjiang (ZJ) & 24 & 1 & 0.000 & 0.00000 & 0.000 & 8 & 8 & 1.000 & 0.00372 & 1.179 \\
\hline Beihai (BH) & 14 & 2 & 0.264 & 0.00053 & 0.264 & 14 & 13 & 0.989 & 0.00333 & 1.055 \\
\hline Sanya (SY) & 22 & 13 & 0.892 & 0.01185 & 5.926 & $11(24)$ & 16 & 0.935 & 0.00937 & 2.953 \\
\hline
\end{tabular}

( $n=121$, accounting for $67.6 \%$ of all individuals; Table 3). The mean number of pairwise differences varied greatly among populations, ranging from 0 in Yangjiang and Zhanjiang (YJ and ZJ, respectively; $\left.\pi_{\mathrm{COI}}=0\right)$ to 28.04 in ST $\left(\pi_{\mathrm{COI}}=0.0561\right.$; Table 2$)$.

The ncITS sequence contained an ambiguous region (after position 2330 ) due to a poly- $\mathrm{T}$ at positions 296 to 310 . This region was uniformly cut off for each sequence and left $\sim 320$ bp long fragments. The final alignment includes 47 polymorphic sites, resulting in 96 different haplotypes from 145 sequences. The nuclear data set for Tegillarca granosa is characterized by high genetic variation, similar to other marine bivalves (e.g. subgenus Acar; Marko \& Moran 2009) as well as freshwater bivalves (Mulvey et al. 1998). Overall, haplotype diversity of ncITS was considerably higher than that of the mtCOI gene, ranging from 0.800 to 1.000 for ncITS (Table 2).

Pairwise $\Phi_{\mathrm{ST}}$ using the combined mtCOI and ncITS sequences showed the existence of clear population structure within and between the 2 seas (Table 4). Three populations (Xiamen [XM], ST, and SY) were highly different from all other populations with all pairwise $\Phi_{\mathrm{ST}}$ values being significant (Table 4). No significant correlation existed between genetic and geographic distances ( $p=0.068, r^{2}=0.069$; Fig. 2), even when the northern and southern populations of the northern lineage were analysed separately (northern populations: $\mathrm{p}=0.612, \mathrm{r}^{2}=0.038$; southern populations: $\mathrm{p}=0.393, \mathrm{r}^{2}=0.018$; data not shown), indicating the gene exchange along the coastline did not fit the isolation-by-distance model.

Different phylogenetic methods yielded identical topologies for mtCOI sequences as 2 reciprocally monophyletic lineages were apparent in both analy-
Table 3. Distribution of 33 unique haplotypes of cytochrome C oxidase subunit I sequences across 10 sampled populations (see Table 2 for abbreviations). Tot. n: total no. of individuals with the haplotype; Tot. pop.: total no. of populations with individuals having the haplotype

\begin{tabular}{|lccc|}
\hline Haplotype & Site (no. ind.) & Tot. n & Tot. pop. \\
\hline Hap.01 & WH (14), SS (5), WZ (16), & 121 & 9 \\
& XP (14), XM (25), YJ (4), & & \\
& ZJ (24), BH (12), SY (7) & & \\
Hap.02 & WH (3), WZ (2), XP (6) & 11 & 3 \\
Hap.03 & WH (3) & 3 & 1 \\
Hap.04 & SS (1) & 1 & 1 \\
Hap.05 & WZ (1) & 1 & 1 \\
Hap.06 & XP (1) & 1 & 1 \\
Hap.07 & XM (1) & 1 & 1 \\
Hap.08 & ST (1) & 1 & 1 \\
Hap.09 & ST (6) & 6 & 1 \\
Hap.10 & ST (3) & 3 & 1 \\
Hap.11 & ST (1) & 1 & 1 \\
Hap.12 & ST (1) & 1 & 1 \\
Hap.13 & ST (1) & 1 & 1 \\
Hap.14 & ST (1) & 1 & 1 \\
Hap.15 & ST (1) & 4 & 1 \\
Hap.16 & ST (4) & 1 & 1 \\
Hap.17 & ST (1) & 1 \\
Hap.18 & ST (1) & 1 & 1 \\
Hap.19 & ST (1) & 1 & 1 \\
Hap.20 & ST (1) & 1 & 1 \\
Hap.21 & BH (2) & 1 & 1 \\
Hap.22 & SY (1) & 1 & 1 \\
Hap.23 & SY (1) & 1 & 1 \\
Hap.24 & SY (2) & 1 \\
Hap.25 & SY (3) & 1 \\
Hap.26 & SY (1) & 1 \\
Hap.27 & SY (1) & 1 \\
Hap.28 & SY (1) & 1 \\
Hap.29 & SY (1) & 1 \\
Hap.30 & SY (1) & 1 \\
Hap.31 & SY (1) & 1 \\
Hap.32 & SY (1) & 1 \\
Hap.33 & SY (1) & 1 \\
\hline
\end{tabular}


Table 4. Tegillarca granosa. Pairwise $\Phi_{\mathrm{ST}}$ among 10 clam populations (see Table 2 for abbreviations) along the Chinese coast using combined mtCOI and ncITS sequences. ${ }^{*} \mathrm{p}<0.05$ after 10000 permutations

\begin{tabular}{|c|c|c|c|c|c|c|c|c|c|}
\hline \multirow[t]{2}{*}{ Population } & \multicolumn{5}{|c|}{-East China Sea- } & \multicolumn{4}{|c|}{ - South China Sea- } \\
\hline & WH & SS & WZ & XP & $\mathrm{XM}$ & ST & YJ & ZJ & $\mathrm{BH}$ \\
\hline SS & -0.001 & - & & & & & & & \\
\hline WZ & 0.034 & 0.070 & - & & & & & & \\
\hline XP & -0.007 & 0.076 & $0.235^{*}$ & - & & & & & \\
\hline $\mathrm{XM}$ & $0.432^{*}$ & $0.534^{*}$ & $0.585^{*}$ & $0.501^{*}$ & - & & & & \\
\hline ST & $0.508^{*}$ & $0.456^{*}$ & $0.499^{*}$ & $0.521^{*}$ & $0.551^{*}$ & - & & & \\
\hline YJ & 0.062 & 0.208 & 0.196 & $0.271^{*}$ & $0.493^{*}$ & $0.433^{*}$ & - & & \\
\hline ZJ & 0.042 & 0.131 & -0.104 & $0.219^{*}$ & $0.554^{*}$ & $0.486^{*}$ & 0.161 & - & \\
\hline $\mathrm{BH}$ & $0.087^{*}$ & 0.023 & -0.014 & $0.212^{*}$ & $0.524^{*}$ & $0.521^{*}$ & 0.163 & -0.046 & - \\
\hline SY & $0.632^{*}$ & $0.588^{*}$ & $0.636^{*}$ & $0.643^{*}$ & $0.691^{*}$ & $0.718^{*}$ & $0.577^{*}$ & $0.613^{*}$ & $0.646^{*}$ \\
\hline
\end{tabular}

ses (only the network is shown here; Fig. 3a). By including 14 sequences from Zheng et al. (2009) in the tree analysis, we show that the 2 lineages here were concordant with formerly identified ECS versus SCS lineages (Zheng et al. 2009). Lineage COI-E (presumed to originate from the ECS), with 29 haplotypes and 170 individuals in total (Table 5), dominated the 10 populations over the whole range of this species (Fig. 1). By contrast, lineage COI-S (presumed to originate from the SCS) was geographically restricted to the 2 SCS populations ST and SY, with 9 individuals in total (Table 5). The net average genetic distance $( \pm \mathrm{SD})$ between lineages was $d_{\text {COI-E/S }}=7.79 \pm$ $1.07 \%$, while the mean sequence divergence within lineage was $0.91 \pm 0.22 \%$ for COI-E and $2.30 \pm$ $0.47 \%$ for COI-S, respectively. Only 4 haplotypes

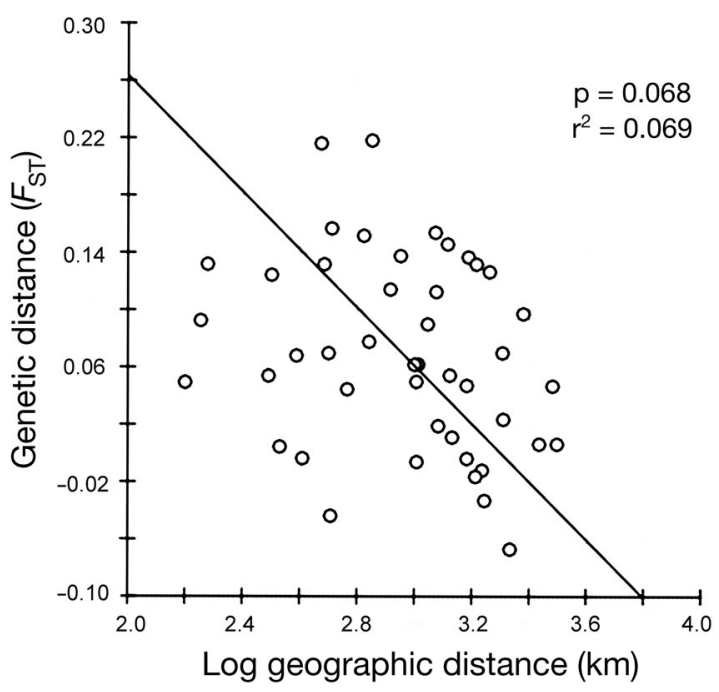

Fig. 2. Tegillarca granosa. Relationship of pairwise population genetic vs. geographic distance among 10 populations (see Table 2 for abbreviations) along the coast of China were found for COI-S, and more than 18 steps are required to connect Haplotype 31 with the other 3 haplotypes (Fig. 3a).

Two divergent lineages were revealed in both ncITS phylogenetic analyses (namely ITS-E and ITS-S), and the relationships between them are presented in the network (Fig. 3b). ITS-E consisted of 59 haplotypes (82 sequences) and was distributed over 8 populations (Fig. 1), while ITS-S with 37 haplotypes and 63 sequences dominated ST and SY populations (Table 5). The 2 nuclear lineages were separated by an average $( \pm \mathrm{SD}) d_{\text {ITS-E/S }}=2.61 \pm 0.83 \%$ sequence divergence. Within lineage sequence diversity was $d_{\text {ITS-E }}=0.44 \pm 0.17 \%$ for ITS-E and $d_{\text {ITS-S }}=0.76 \pm$ $0.20 \%$ for ITS-S, respectively. No spatial overlap was revealed for the 2 lineages in any population.

\section{DISCUSSION}

\section{Interpreting phylogeographic patterns}

In East Asia, the long separation of ECS and SCS served as a barrier against dispersal of most marine taxa, with similar consequences for genetic dispersal of various species such as red lip mullet Chelon haematocheilus (Liu et al. 2007), mitten crab Eriocheir sensu stricto (Xu et al. 2009), and bivalves (Coelomactra antiquata, Kong \& Li 2009; Cyclina sinensis, authors' unpubl. data). In order to better understand the phylogeographic pattern of Tegillarca granosa, we compared the dispersal ability, divergence time, and genetic distribution among $T$. granosa and the other 4 species (Table 6, Fig. 4). The split of divergent lineages for the marine fish and the mitten crab started from approximately the middle Pleistocene, while the estimated divergence time for 
the 3 bivalves is more ancient, starting about $3 \mathrm{Myr}$ ago. Based on a generalized molecular clock $(2 \%$ $\mathrm{Myr}^{-1}$ ) and the estimated mtCOI divergence rate for teguline gastropods $\left(2.4 \% \mathrm{Myr}^{-1}\right.$; Hellberg \& Vac-

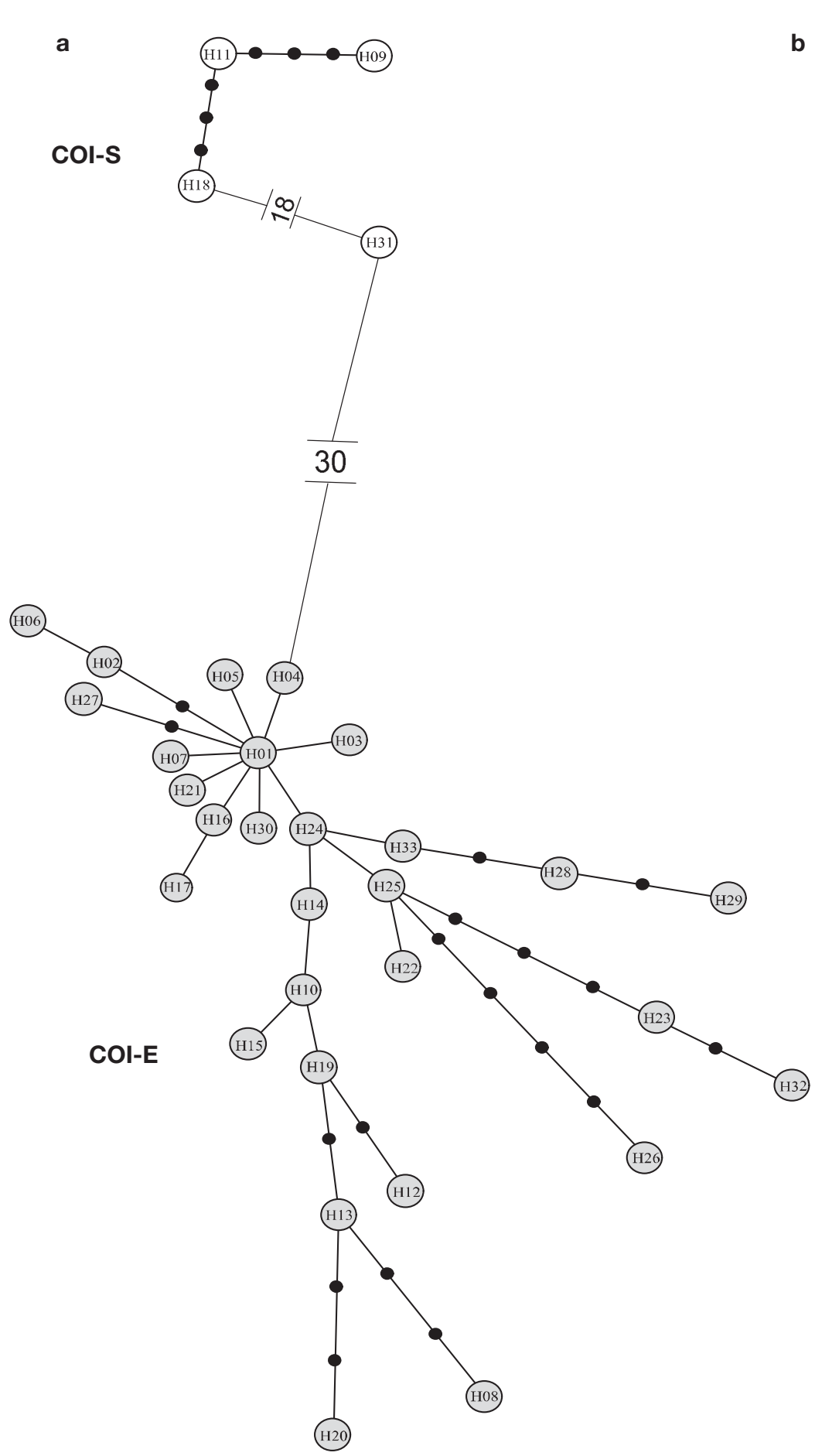

quier 1999), the divergence point of T. granosa COI lineages was estimated to have occurred $\sim 3.3$ to 3.9 Myr ago), which corresponds to the early onset of Northern Hemisphere glaciation around 3.5 Myr ago

b

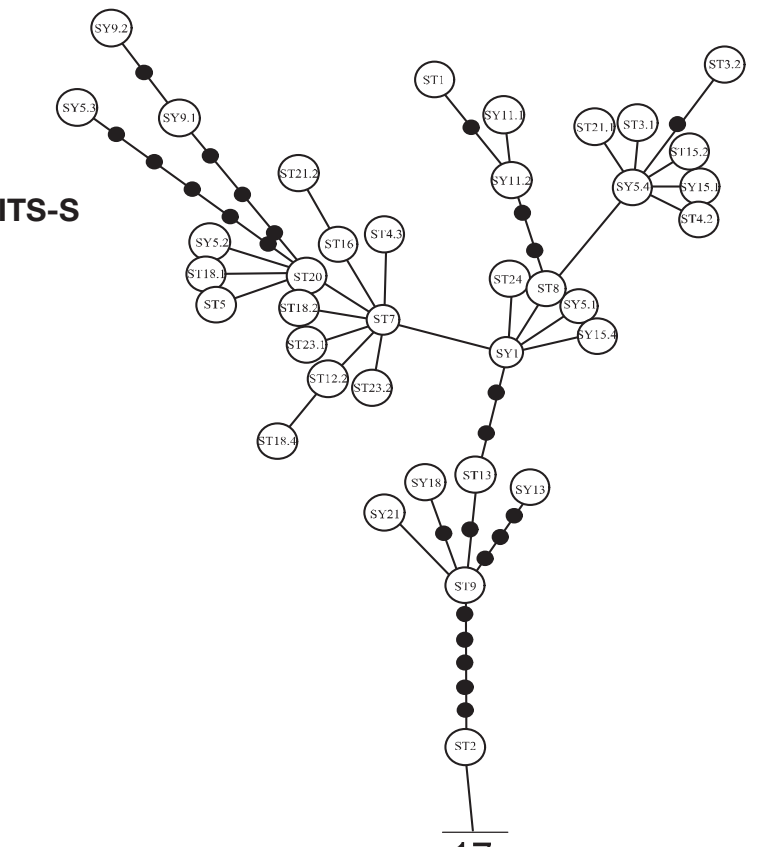

Fig. 3. Tegillarca granosa. Minimum spanning network showing genetic relationships among haplotypes (H) in (a) COI-E and COI-S, and (b) ITS-E and ITS-S lineages (see Table 2 for location abbreviation). Numbers and black dots indicate number of mutational steps between haplotypes. COI: cytochrome $c$ oxidase subunit I; ITS: internal transcribed spacer; -E and -S: putative ancestral East and South China sea lineages, respectively 
Table 5. Summary of molecular diversity for cytochrome $c$ oxidase subunit I (COI-E and -S lineages) and internal transcribed spacer 1 (ITS-E and -S lineages). $N$ : number of individuals sequenced per population per locus (parentheses: total number of sequences; some individuals had $>1$ sequence); $n$ : number of haplotypes; $h$ : haplotype diversity; $\pi$ : nucleotide diversity; $k$ : number of pairwise differences; $d$ : sequence divergence within and between the major lineages of each marker. $d_{\mathrm{COI}-\mathrm{E} / \mathrm{S}}$ and $d_{\text {ITS-E/S }}$ were calculated using net genetic distance. Data: mean \pm SD where indicated

\begin{tabular}{|lcrrrrr|}
\hline & $N$ & $n$ & $h$ & $\pi$ & \multicolumn{1}{c|}{$k$} & $d(\%)$ \\
\hline COI (all) & 179 & 33 & $0.539 \pm 0.046$ & $0.01238 \pm 0.00645$ & $6.19 \pm 2.95$ & $d_{\text {COI-E/S }}=7.79 \pm 1.07$ \\
COI-E & 170 & 29 & $0.490 \pm 0.048$ & $0.00297 \pm 0.00200$ & $1.49 \pm 0.90$ & $d_{\text {COI-E }}=0.91 \pm 0.22$ \\
COI-S & 9 & 4 & $0.583 \pm 0.183$ & $0.01344 \pm 0.00794$ & $6.72 \pm 3.50$ & $d_{\text {COI-S }}=2.30 \pm 0.47$ \\
ITS (all) & $116(145)$ & 96 & $0.986 \pm 0.004$ & $0.0431 \pm 0.02150$ & $14.31 \pm 6.45$ & $d_{\text {ITS-E/S }}=2.61 \pm 0.83$ \\
ITS-E & 82 & 59 & $0.986 \pm 0.006$ & $0.01108 \pm 0.00630$ & $3.57 \pm 1.83$ & $d_{\text {ITS-E }}=0.44 \pm 0.17$ \\
ITS-S & $34(63)$ & 37 & $0.948 \pm 0.019$ & $0.01155 \pm 0.00655$ & $3.73 \pm 1.91$ & $d_{\text {ITS-S }}=0.76 \pm 0.20$ \\
& & & & & &
\end{tabular}

(Meyers \& Hinnov 2010). Comparison of phylogeographic structures patterns among co-distributed species can provide insights into the common historical and/or contemporary oceanographic factors shaping the genetic structures on a regional scale (Kojima et al. 2004). In the northwestern Pacific region, deep intraspecific genetic divergences uniformly displayed in these organisms suggest a close relationship between genetic patterns and the isolation of 2 marginal seas during Plio-Pleistocene climate oscillations.

Despite the different life histories and PLDs among the 4 species we compared with Tegillarca granosa (Table 6), the present 2 marginal sea lineages within these 4 species primarily exhibited an ECS versus SCS distribution (Fig. 4). Even for the marine fish with high dispersal potential (red lip mullet, PLD: $4 \mathrm{wk})$, genetic homogeneity for populations in the 2 seas was not achieved. Secondary contact of diverged lineages by post-glacial dispersal was only observed for populations in the adjacent region of the 2 seas $\left(\sim 23^{\circ}\right.$ to $\left.32^{\circ} \mathrm{N}\right)$. The PLD of T. granosa is similar to that of the other 2 bivalves and much shorter than that of the red lip mullet and the mitten crab (Table 6). In addition, based on habitat preferences, T. granosa does not appear to be a generalist (Table 6). Along with its benthic adult stage, these factors suggest that $T$. granosa does not have the

Table 6. Genetic distribution, divergence time, and life history information on 5 co-distributed species in 2 marginal seas (ECS: East China Sea; SCS: South China Sea). PLD: plankton larval duration; Kyr: $10^{3}$ yr; Myr: $10^{6}$ yr; COI: cytochrome $c$ oxidase subunit I; Cytb:

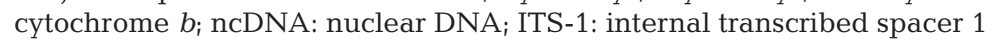

\begin{tabular}{|c|c|c|c|c|c|c|}
\hline Species & PLD & Habitat preference & $\begin{array}{l}\text { Molecular } \\
\text { marker }\end{array}$ & $\begin{array}{l}\text { Divergence time } \\
\text { (substitution rate) }\end{array}$ & $\begin{array}{l}\text { Spatial distribution } \\
\text { of lineages }\end{array}$ & Source \\
\hline \multicolumn{7}{|l|}{ Fish } \\
\hline $\begin{array}{l}\text { Chelon } \\
\text { haematocheilus }\end{array}$ & $4 \mathrm{wk}$ & $\begin{array}{l}\text { Shallow coastal water as } \\
\text { well as estuaries }\end{array}$ & $\begin{array}{l}\text { mtDNA: } \\
\text { control region }\end{array}$ & $\begin{array}{l}\sim 235-783 \mathrm{Kyr}^{-1} \\
\left(3-10 \% \mathrm{Myr}^{-1}\right)\end{array}$ & $\begin{array}{l}\text { Primarily exhibited an ECS vs. } \\
\text { SCS distribution ( } 2 \text { distinct } \\
\text { lineages in the } 2 \text { seas) with a } \\
\text { secondary contact zone around } \\
30^{\circ} \mathrm{N} \text { (Fig. } 4 \mathrm{a} \text { ) }\end{array}$ & Liu et al. (2007) \\
\hline \multicolumn{7}{|l|}{ Mitten crab } \\
\hline $\begin{array}{l}\text { Eriocheir sensu } \\
\text { stricto }\end{array}$ & $\begin{array}{l}\text { Several weeks } \\
\text { (depending on } \\
\text { temperature and } \\
\text { salinity) }\end{array}$ & $\begin{array}{l}\text { Coastal waters during } \\
\text { breeding period }\end{array}$ & $\begin{array}{l}\text { mtDNA: COI } \\
\text { and Cytb }\end{array}$ & $\begin{array}{c}\sim 583-1119 \mathrm{Kyr}^{-1} \\
\left(1.66-2.6 \% \mathrm{Myr}^{-1}\right. \\
\text { for COI })\end{array}$ & $\begin{array}{l}\text { ECS vs. SCS distribution with } \\
\text { extensive secondary contact zone } \\
\text { ranging from } 24 \text { to } 32^{\circ} \mathrm{N} \text { (Fig. } 4 \text { b) }\end{array}$ & Xu et al. (2009) \\
\hline \multicolumn{7}{|l|}{ Bivalve } \\
\hline $\begin{array}{l}\text { Coelomactra } \\
\text { antiquata }\end{array}$ & $\begin{array}{l}\text { 9-14 d (in } \\
\text { laboratory cultures) }\end{array}$ & $\begin{array}{l}\text { Sandy habitats from the } \\
\text { lower intertidal zone to } \\
20 \mathrm{~m} \text { depth }\end{array}$ & $\begin{array}{l}\text { mtDNA: } \\
\text { 16S rRNA }\end{array}$ & $\begin{array}{c}\sim 3 \mathrm{Myr}^{-1} \\
\left(2 \% \mathrm{Myr}^{-1}\right)\end{array}$ & $\begin{array}{l}\text { ECS vs. SCS distribution with no } \\
\text { secondary contact zone detected } \\
\text { (Fig. } 4 \mathrm{c} \text { ) }\end{array}$ & Kong \& Li (2009) \\
\hline $\begin{array}{l}\text { Cyclina } \\
\text { sinensis }\end{array}$ & $6-9 d$ & $\begin{array}{l}\text { Muddy sand beaches of } \\
\text { the intertidal zone }\end{array}$ & $\begin{array}{l}\text { ncDNA: } \\
\text { ITS-1 }\end{array}$ & $\begin{array}{c}\sim 2.05-3.08 \mathrm{Myr} \\
\left(2-3 \% \mathrm{Myr}^{-1}\right)\end{array}$ & $\begin{array}{l}\text { ECS vs. SCS distribution with a } \\
\text { secondary contact zone around } \\
23^{\circ} \mathrm{N} \text { (Fig. } 4 \mathrm{~d} \text { ) }\end{array}$ & $\begin{array}{l}\text { Authors' unpubl. } \\
\text { data }\end{array}$ \\
\hline $\begin{array}{l}\text { Tegillarca } \\
\text { granosa }\end{array}$ & $\sim 15 \mathrm{~d}$ & $\begin{array}{l}\text { Subtidal/intertidal } \\
\text { mudflats }\end{array}$ & $\begin{array}{l}\text { mtDNA: } \\
\text { COI }\end{array}$ & $\begin{array}{c}\sim 3 .-3.9 \mathrm{Myr}^{-1} \\
\left(2-2.4 \% \mathrm{Myr}^{-1}\right)\end{array}$ & $\begin{array}{l}\text { One lineage was widely } \\
\text { distributed in both seas, and } \\
\text { another one was restricted in } 2 \\
\text { populations in SCS (Fig. 4e) }\end{array}$ & Present study \\
\hline
\end{tabular}




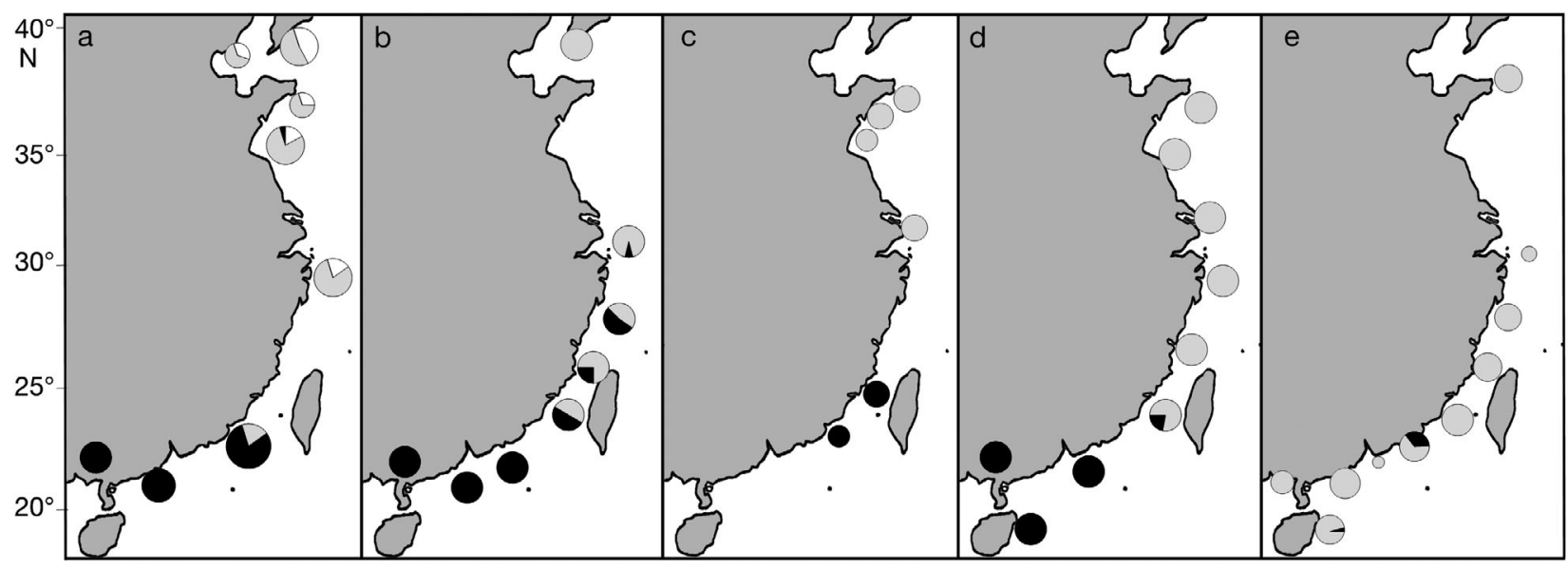

Fig. 4. Genetic distribution of 5 sympatric marine species. Pie charts: gray = East China Sea lineage, black = South China Sea lineage, white = Japan Sea lineage. (a) Redlip mullet Chelon haematocheilus (redrawn from Liu et al. 2007); (b) mitten crab Eriocheir sensu stricto (redrawn from Xu et al. 2009); (c) clam Coelomactra antiquata (redrawn from Kong \& Li 2009); (d) clam Cyclina sinensis (authors' unpubl. data); (e) clam Tegillarca granosa (present study)

capacity for dispersal on a large spatial scale and an ECS versus SCS distribution of the 2 marginal sea lineages of this species would be expected. However, in our study, one T. granosa lineage that dominated the ECS populations was also found widely distributed in the SCS, even in the southernmost populations. Natural processes such as gene flow via clam dispersal by ocean currents apparently did not drive this pattern, and the population structure also does not fit the IBD model. Considering the present oceanographic features in the ECS and SCS, with small but persistent reciprocal flows and rotating flows along coastal areas (ECCBR 1993), clam dispersal via ocean currents may be low since larvae either are not exposed to the major currents or are transported only ineffectively. Therefore, human-mediated passive dispersal via aquaculture activities is the most likely explanation for this disordered genetic distribution. Given that most bivalves experience a 'sweepstakes' mode of reproduction and survival (Avise 1998), even a small number of individuals surviving translocation may contribute greatly to the next generation, with the potential to dramatically change the native genetic structure. Such a case has been reported for pearl oysters in French Polynesia, where homogenization of the previously genetically distinct wild stocks occurred as a result of juvenile collection and translocation (Arnaud-Haond et al. 2004). However, since coastal marine species readily spread all over the newly colonized region in some cases (e.g. Cárdenas et al. 2009), the natural range expansion hypothesis for T. granosa cannot be fully ruled out unless more evidence is obtained.

\section{Delineating ESUs within Tegillarca granosa}

Although differentiation between ECS and SCS populations of Tegillarca granosa has been reported (e.g. Li et al. 2003, Zheng et al. 2009), the status of the 2 divergent groups is still a matter of controversy. In the present study, we tried to resolve the issue based on evidence from both mtCOI and ncITS markers.

The mtCOI-based phylogenetic analyses revealed 2 major divergent lineages using Bayesian inference as well as 2 haplogroups in the corresponding minimum spanning network. The net average genetic distance between the 2 lineages reached up to $7.79 \%$, which is within the range reported for mitochondrial genes among cryptic species in other bivalves (e.g. Spisula solidissima, Hare \& Weinberg 2005; Brachidontes variabilis, Terranova et al. 2007; Coelomactra antiquata, Kong \& Li 2009). The nuclear locus also showed 2 well supported lineages in the Bayesian tree and the network. Genetic distance between these 2 lineages $\left(d_{\text {ITS-E/S }}=2.61 \%\right)$ is 6 times larger than that within ITS-E and 3 times larger than that within ITS-S (Table 5).

Based on our results, and significant divergences of other nuclear allele frequencies observed between the 2 lineages in other studies (RAPD, Li et al. 2003; isozyme, Wang et al. 2005), we conclude that 2 separate ESUs sensu Moritz (1994) exist within the bivalve Tegillarca granosa in the 2 China seas. Delineating any ESUs within species is the first step of species' management (Frankham et al. 2002), and has direct implications for conservation decisions (e.g. Lecis \& Norris 2004, Holycross \& Douglas 2007, 
Campbell et al. 2009, Koumoundouros et al. 2009). The $2 T$. granosa ESUs we identify here can aid sustainable management of this clam by helping to define conservation priorities (e.g. avoiding translocation of individuals between ESUs) and setting a long-term strategy.

\section{Conservation implications and conclusion}

Conserving historical lineages, maintaining evolutionary processes, and ensuring the persistence of populations are 3 major goals of conservation (Lourie 2004). In marine realms, there have been numerous recent examples of genetic studies applied to the evaluation and conservation of threatened intraspecific diversity (e.g. seahorse, Teske et al. 2003; turtle, Shanker et al. 2004; bivalve, Lind et al. 2007; stickleback, Cano et al. 2008). For Tegillarca granosa, our results show that the initial ESU in the SCS is now distributed in small and fragmented populations. Moreover, mitochondrial introgression from northern to southern lineage has been observed in 6 individuals in the ST population and 5 individuals in the SY population (data not shown). The southern populations may be affected by outbreeding, although there was no evidence for nuclear hybrids. Mitochondrial introgression frequently occurs without any evidence of nuclear introgression or morphological signal (see review in Ballard \& Whitlock 2004, Kemppainen et al. 2009). These factors may indirectly contribute to the extinction risk of the southern ESU. Immediate conservation efforts are necessary to preserve populations representing the southern lineage, because once lost, an evolutionary lineage will never be recovered (Moritz 2002). On the other hand, preserving the southern lineage will also ensure the potential of genetic improvement for the clam if needed in the future, e.g. in the case of biodiversity loss in aquaculture.

With continued anthropogenic pressure on marine fisheries and ocean resources, coastal species-as the most commercially exploited-are increasingly affected by human activities (Liu 2009). In East Asia, recent concerns mainly concentrate on the effects of mariculture on economic development (Zhang et al. 2003) and the coastal environment (Feng et al. 2004, Liu 2009), while the subsequent genetic effects on biodiversity are often ignored, leading to sub-optimal management and in some cases to disastrous decisions (e.g. the conservation management for Coelomactra antiquata; Kong \& Li 2009). Collecting juvenile clams from a wild population and translocating them to supplement another population without any relevant information on the genetic composition and level of variability between the source and target populations can lead to the mixing of diverged gene pools (Arnaud-Haond et al. 2004; also Tegillarca granosa in the present study).

The lack genetic monitoring is a common issue in the process of translocation and/or breeding of commercially important coastal species (Huvet et al. 2000, Arnaud-Haond et al. 2004, Kong \& Li 2009). The results of our study in China's coastal areas indicate a need for more empirical studies focusing on the effects of human activities on genetic diversity of commercially exploited species in coastal environments worldwide. This information is not only of great interest to conservation genetics, but can also yield valuable insights into the sustainable development of aquaculture and fisheries.

Acknowledgements. We are indebted to J. Chen from Ocean University of China for his kind assistance in specimen collection. Our study was supported by research grants from the National Natural Science Foundation of China (grant nos. 31072207, 40906064), and Shandong Seed Project.

\section{LITERATURE CITED}

Allendorf FW, Luikart G (2007) Conservation and the genetics of populations. Wiley-Blackwell, Oxford

Arnaud-Haond S, Vonau V, Bonhomme F, Boudry P and others (2004) Spatio-temporal variation in the genetic composition of wild populations of pearl oyster (Pinctada margaritifera cumingii) in French Polynesia following 10 years of juvenile translocation. Mol Ecol 13:2001-2007

Avise JC (1998) Conservation genetics in the marine realm. J Hered 89:377-382

> Ballard JWO, Whitlock MC (2004) The incomplete natural history of mitochondria. Mol Ecol 13:729-744

> Benke M, Brändle M, Albrecht C, Wilke T (2009) Pleistocene phylogeography and phylogenetic concordance in coldadapted spring snails (Bythinella spp.). Mol Ecol 18: 890-903

Campbell S, Guay PJ, Mitrovski PJ, Mulder R (2009) Genetic differentiation among populations of a specialist fishing bat suggests lack of suitable habitat connectivity. Biol Conserv 142:2657-2664

Cano JM, Mäkinen HS, Leinonen T, Freyhof J, Merilä J (2008) Extreme neutral genetic and morphological divergence supports classification of Adriatic three-spined stickleback (Gasterosteus aculeatus) populations as distinct conservation units. Biol Conserv 141:1055-1066

Cárdenas L, Castilla JC, Viard F (2009) A phylogeographical analysis across three biogeographical provinces of the south-eastern Pacific: the case of the marine gastropod Concholepas concholepas. J Biogeogr 36:969-981

Cheang CC, Chu KH, Ang PO (2010) Phylogeography of the marine macroalga Sargassum hemiphyllum (Phaeophyceae, Heterokontophyta) in northwestern Pacific. Mol Ecol 19:2933-2948 
ECCBR (Edit Committee of China Bay Records) (1993) China Bay Records. Ocean Press, Beijing

Excoffier L, Lischer HEL (2010) Arlequin suite ver 3.5: a new series of programs to perform population genetics analyses under Linux and Windows. Mol Ecol Resour 10: 564-567

Feng YY, Hou LC, Ping NX, Ling TD, Kyo CI (2004) Development of mariculture and its impacts in Chinese coastal waters. Rev Fish Biol Fish 14:1-10

> Flot J (2007) Champuru 1.0: a computer software for unraveling mixtures of two DNA sequences of unequal lengths. Mol Ecol Notes 7:974-977

> Folmer O, Black M, Hoeh W, Lutz R, Vrijenhoek R (1994) DNA primers for amplification of mitochondrial cytochrome $c$ oxidase subunit I from diverse metazoan invertebrates. Mol Mar Biol Biotechnol 3:294-299

> Frankham R (2010) Challenges and opportunities of genetic approaches to biological conservation. Biol Conserv 143: 1919-1927

Frankham R, Briscoe DA, Ballou JD (2002) Introduction to conservation genetics. Cambridge University Press, Cambridge

Gaffney PM, Orbacz EA, Yu Z (1998) Using the DCode ${ }^{\mathrm{TM}}$ system to identify DNA sequence variation for studies of population structure in marine organisms. BIORAD Mutat Anal Tech Note 2329, available at www3.biorad.com/webmaster/pdfs/Bulletin_2329.pdf

> Guindon S, Gascuel O (2003) A simple, fast, and accurate algorithm to estimate large phylogenies by maximum likelihood. Syst Biol 52:696-704

> Haq BU, Hardenbol J, Vail PR (1987) Chronology of fluctuating sea levels since the Triassic. Science 235:1156-1167

> Hare MP, Weinberg JR (2005) Phylogeography of surfclams, Spisula solidissima, in the western North Atlantic based on mitochondrial and nuclear DNA sequences. Mar Biol 146:707-716

> Hellberg ME (2009) Gene flow and isolation among populations of marine animals. Annu Rev Ecol Evol Syst 40: 291-310

> Hellberg ME, Vacquier VD (1999) Rapid evolution of fertilization selectivity and lysin cDNA sequences in teguline gastropods. Mol Biol Evol 16:839-848

> Hoban SM, Borkowski DS, Brosi SL, McCleary TM and others (2010) Range-wide distribution of genetic diversity in the North American tree Juglans cinerea: a product of range shifts, not ecological marginality or recent population decline. Mol Ecol 19:4876-4891

> Holycross A, Douglas M (2007) Geographic isolation, genetic divergence, and ecological non-exchangeability define ESUs in a threatened sky-island rattlesnake. Biol Conserv 134:142-154

> Hu ZM, Li W, Li JJ, Duan DL (2011) Post-Pleistocene demographic history of the North Atlantic endemic Irish moss Chondrus crispus: glacial survival, spatial expansion and gene flow. J Evol Biol 24:505-517

> Huelsenbeck JP, Ronquist F (2001) MRBAYES: Bayesian inference of phylogenetic trees. Bioinformatics 17: 754-755

> Huvet A, Lapegue S, Magoulas A, Boudry P (2000) Mitochondrial and nuclear DNA phylogeography of Crassostrea angulata, the Portuguese oyster endangered in Europe. Conserv Genet 1:251-262

> Jensen JL, Bohonak AJ, Kelley ST (2005) Isolation by distance, web service. BMC Genet 6:13, doi:10.1186/14712156-6-13
Kemppainen P, Panova M, Hollander J, Johannesson K (2009) Complete lack of mitochondrial divergence between two species of NE Atlantic marine intertidal gastropods. J Evol Biol 22:2000-2011

> Kimura M (2000) Paleogeography of the Ryukyu Islands. Tropics 10:5-24

> Kochzius M, Seidel C, Hauschild J, Kirchhoff S and others (2009) Genetic population structures of the blue starfish Linckia laevigata and its gastropod ectoparasite Thyca crystallina. Mar Ecol Prog Ser 396:211-219

Kojima S, Hayashi I, Kim D, Iijima A, Furota T (2004) Phylogeography of an intertidal direct-developing gastropod Batillaria cumingi around the Japanese Islands. Mar Ecol Prog Ser 276:161-172

> Kong LF, Li Q (2009) Genetic evidence for the existence of cryptic species in an endangered clam Coelomactra antiquata. Mar Biol 156:1507-1515

> Koumoundouros T, Sumner J, Clemann N, Stuart-Fox D (2009) Current genetic isolation and fragmentation contrasts with historical connectivity in an alpine lizard (Cyclodomorphus praealtus) threatened by climate change. Biol Conserv 142:992-1002

> Lecis R, Norris K (2004) Population genetic diversity of the endemic Sardinian newt Euproctus platycephalus: implications for conservation. Biol Conserv 119:263-270

Lee HJ, Boulding EG (2009) Spatial and temporal population genetic structure of four northeastern Pacific littorinid gastropods: the effect of mode of larval development on variation at one mitochondrial and two nuclear DNA markers. Mol Ecol 18:2165-2184

Li Q, Park C, Kijima A (2002) Isolation and characterization of microsatellite loci in the Pacific abalone, Haliotis discus hannai. J Shellfish Res 21:811-816

Li TW, Li CH, Song LS, Su XR (2003) RAPD variation within and among five populations of Tegillarca granosa. Biodiversity Sci 11:118-124 (in Chinese with English Abstract)

Lind CE, Evans BS, Taylor JJU, Jerry DR (2007) Population genetics of a marine bivalve, Pinctada maxima, throughout the Indo-Australian Archipelago shows differentiation and decreased diversity at range limits. Mol Ecol 16: 5193-5203

> Liu JX, Gao TX, Wu SF, Zhang YP (2007) Pleistocene isolation in the northwestern Pacific marginal seas and limited dispersal in a marine fish, Chelon haematocheilus (Temminck \& Schlegel, 1845). Mol Ecol 16:275-288

Liu RY (2009) Present status of marine biodiversity of the China seas. Ocean Ecology Protection and Modern Fishery Management Seminar, Qingdao

Lourie SA (2004) Phylogeography of Southeast Asian seahorses in a conservation context. $\mathrm{PhD}$ thesis, McGill University, Montreal

Marko PB (2004) 'What's larvae got to do with it?' Disparate patterns of post-glacial population structure in two benthic marine gastropods with identical dispersal potential. Mol Ecol 13:597-611

> Marko PB, Moran AL (2009) Out of sight, out of mind: high cryptic diversity obscures the identities and histories of geminate species in the marine bivalve subgenus Acar. J Biogeogr 36:1861-1880

> Meyers SR, Hinnov LA (2010) Northern Hemisphere glaciation and the evolution of Plio-Pleistocene climate noise. Paleoceanography 25:PA3207

> Moritz C (1994) Defining 'Evolutionarily Significant Units' for conservation. Trends Ecol Evol 9:373-375

> Moritz C (2002) Strategies to protect biological diversity and 
the evolutionary processes that sustain it. Syst Biol 51: 238-254

Mulvey M, Liu HP, Kandl KL (1998) Application of molecular genetic markers to conservation of freshwater bivalves. J Shellfish Res 17:1395-1405

Posada D (2008) jModelTest: phylogenetic model averaging. Mol Biol Evol 25:1253-1256

Shanker K, Ramadevi J, Choudhury BC, Singh L, Aggarwal RK (2004) Phylogeography of olive ridley turtles (Lepidochelys olivacea) on the east coast of India: implications for conservation theory. Mol Ecol 13:1899-1909

Sponaugle S, Cowen RK, Shanks A, Morgan SG and others (2002) Predicting self-recruitment in marine populations: biophysical correlates and mechanisms. Bull Mar Sci 70: 341-375

Tamura K, Peterson D, Peterson N, Stecher G, Nei M, Kumar S (2011) MEGA5: molecular evolutionary genetics analysis using maximum likelihood, evolutionary distance, and maximum parsimony methods. Mol Biol Evol 28: 2731-2739

Teacher AGF, Griffiths DJ (2011) HapStar: automated haplotype network layout and visualization. Mol Ecol Resour 11:151-153

Terranova MS, Brutto SL, Arculeo M, Mitton JB (2007) A mitochondrial phylogeography of Brachidontes variabilis (Bivalvia: Mytilidae) reveals three cryptic species. J Zool Syst Evol Res 45:289-298

Teske PR, Cherry MI, Matthee CA (2003) Population genetics of the endangered Knysna seahorse, Hippocampus capensis. Mol Ecol 12:1703-1715

Tsang LM, Chan BKK, Ma KY, Chu KH (2008) Genetic differentiation, hybridization and adaptive divergence in two subspecies of the acorn barnacle Tetraclita japonica in the northwestern Pacific. Mol Ecol 17:4151-4163

Editorial responsibility: Karen Miller,

Hobart, Tasmania, Australia
Utter F (2000) Patterns of subspecific anthropogenic introgression in two salmonid genera. Rev Fish Biol Fish 10: 265-279

Wang PX, Sun XJ (1994) Last glacial maximum in China: comparison between land and sea. Catena 23:341-353

Wang RX, Li TW, L ZM, Su XR, Lin ZH, Chai XR (2005) Study on genetic variation by isozyme in different populations of bloody clam Tegillarca granosa. Oceanol Limnol Sin 3:227-234 (in Chinese with English Abstract)

> Wares JP (2002) Community genetics in the Northwestern Atlantic intertidal. Mol Ecol 11:1131-1144

- Xiao J, Cordes J, Wang H, Guo X, Reece K (2010) Population genetics of Crassostrea ariakensis in Asia inferred from microsatellite markers. Mar Biol 157:1767-1781

Xu FS (1997) Bivalve Mollusca of China Seas. Science Press, Beijing

> Xu J, Chan TY, Tsang LM, Chu KH (2009) Phylogeography of the mitten crab Eriocheir sensu stricto in East Asia: Pleistocene isolation, population expansion and secondary contact. Mol Phylogenet Evol 52:45-56

Zhang LX, Liu J, Li SF, Yang NS, Gardiner PR (2003) Agricultural development and the opportunities for aquatic resources research in China. The WorldFish Center, Penang

Zheng JS, Wang ML, Wang ZY, Liu ZH, Cui XZ (1995) Study on the development of sex gonad reproductive cycle of bloody clam Tegillarca granosa Linnaeus. J Ocean Univ Qingdao 4:503-510 (in Chinese with English Abstract)

Zheng WJ, Zhu SH, Shen XQ, Liu BQ, Pan ZC, Ye YF (2009) Genetic differentiation of Tegillarca granosa based on mitochondrial COI gene sequences. Zool Res 30:17-23 (in Chinese with English Abstract)

Zhou M, Allen SK Jr (2003) A review of published work on Crassostrea ariakensis. J Shellfish Res 22:1-2

Submitted: April 11, 2011; Accepted: January 26, 2012

Proofs received from author(s): April 17, 2012 